\title{
Upper gastrointestinal stenting during the SARS-CoV-2 outbreak: impact of mitigation measures and risk of contamination for patients and staff
}

\section{(ㄷ)(우우}

Authors

Eduardo Rodrigues-Pinto*, 1,2, Joel Ferreira-Silva*,1,2, Alessandro Fugazza ${ }^{3,4}$, Antonio Capogreco ${ }^{3,4}$, Alessandro Repici $^{3,4}$, Simon Everett ${ }^{5}$, David Albers ${ }^{6}$, Brigitte Schumacher ${ }^{6}$, Angels Gines ${ }^{7}$, Peter D. Siersema ${ }^{8}$, Guilherme Macedo ${ }^{1,2}$

Institutions

1 Gastroenterology Department, Centro Hospitalar São João, Porto, Portugal

2 Faculty of Medicine of the University of Porto, Porto, Portugal

3 Digestive Endoscopy Unit, Humanitas Clinical and Research Center - IRCCS, Milan, Italy

4 Humanitas University, Department of Biomedical Sciences, Milan, Italy

5 Department of Gastroenterology and Hepatology, Leeds Teaching Hospital NHS Trust, Leeds, United Kingdom

6 Department of Gastroenterology, ElisabethKrankenhaus Essen, Teaching Hospital of the University of Duisburg-Essen, Essen, Germany

7 Endoscopy Unit, Gastroenterology Department, ICMDiM, Hospital Clinic. IDIBAPS. CIBERehd.University of Barcelona, Catalonia, Spain

8 Department of Gastroenterology and Hepatology, Radboud University Medical Center, Nijmegen, The Netherlands

submitted 21.7.2020

accepted after revision 19.10.2020

Bibliography

Endoscopy International Open 2021; 09: E76-E86

DOI 10.1055/a-1319-1201

ISSN 2364-3722

(c) 2021. The Author(s).

This is an open access article published by Thieme under the terms of the Creative Commons Attribution-NonDerivative-NonCommercial License, permitting copying and reproduction so long as the original work is given appropriate credit. Contents may not be used for commecial purposes, or adapted, remixed, transformed or built upon. (https://creativecommons.org/licenses/by-nc-nd/4.0/)

Georg Thieme Verlag KG, Rüdigerstraße 14,

70469 Stuttgart, Germany

Corresponding author

Eduardo Rodrigues-Pinto, MD, Gastroenterology Department, Centro Hospitalar São João, Porto. Al. Prof. Hernâni Monteiro 4200 - 319, Porto, Portugal
Fax: +351225513601

edu.gil.pinto@gmail.com

\section{ABSTRACT}

Background and study aims The impact of COVID-19 mitigation measures on stent placement procedures has not yet been reported. The aim of this study was to assess the impact of COVID-19 mitigation measures on upper stenting during SARS-CoV-2 outbreak, as well as the use of personal protection equipment (PPE) and risk of contamination for patients and staff.

Patients and methods This was a multicenter, retrospective study of consecutive patients who underwent stent placement for upper gastrointestinal obstruction during the second half of SARS-CoV-2 outbreak period in comparison to same period one year before.

Results A total of 29 stents were placed for upper gastrointestinal obstruction during the study period, corresponding to an increase of $241 \%$ comparing to the same period in $2019(n=12)$. No significant major differences were found between the two time periods regarding patients' baseline characteristics, post-stenting management and number of staff involved in stent placement. Fellows' involvement was significantly lower in 2020 compared to 2019 (21\% vs $67 \% ; P=0.01)$. The majority of procedures were performed using FFP2/FFP3 mask (76\%), protective eyewear (86\%), two pairs of gloves (65\%), hairnet (76\%) and full disposable gowns (90\%). One patient tested positive for SARS-CoV-2 after the procedure. None of the medical staff involved in stenting procedures developed COVID-19 14 days after procedure.

Conclusion Upper gastrointestinal stenting increased during the SARS-CoV-2 outbreak period, which could be related to yearly variation on the number of procedures or reflect a change of oncologic treatment practice during COVID times.

\footnotetext{
* These authors contributed equally
} 


\section{Introduction}

The coronavirus disease 2019 (COVID-19) pandemic has placed the world under unprecedented pressure. Gastroenterology departments required drastic reorganization to deal with mitigation measures. Specifically, they were forced to reduce the routine workload to prevent the risk of infection spreading, with consequent quantitative and qualitative impairment of the health services provided and potential impact on patients' healthcare status [1]. Even though mitigation measures resulted in a reduction in the impact of illness on healthcare system capacity, they led to deferral of elective procedures in accordance with recommendations from several society guidelines [2-6].

All endoscopic procedures, especially upper endoscopy, are considered aerosol-generating and adequate personal protection equipment (PPE) should be used [7]. Therapeutic procedures may theoretically increase healthcare professional (HCP) exposure due to their longer duration [8]. Little is known regarding the risk of contamination of patients and HCPs when endoscopic procedures are performed and PPE is used during endoscopic procedures.

Assessment of the overall impact of a crisis such as COVID19 on clinical practice is an essential and complex exercise. Upper gastrointestinal stenting in patients with symptoms of dysphagia/obstruction due to malignant esophageal [9] or gastric outlet obstruction [10] should be considered a high-priority endoscopic procedure [5], which should be performed immediately, or at least within 1 to 2 weeks [5].

The impact of COVID-19 mitigation measures in self-expandable metal stent (SEMS) procedures has not yet been reported. Therefore, the aim of our study was to assess the impact of COVID-19 mitigation measures on upper gastrointestinal stenting during the severe acute respiratory syndrome coronavirus 2 (SARS-CoV-2) outbreak, as well as the use of adequate PPE and risk of contamination for patients and HCP.

\section{Patients and methods}

We conducted a multicenter, retrospective study in six European centers of consecutive patients who underwent stenting for upper gastrointestinal obstruction (excluding biliary obstruction) during the second half of the SARS-CoV-2 outbreak (from the 35th day to the 60th day since the first national SARS-CoV-2 patient was registered) and compared it to the same period 1 year before the SARS-CoV-2 outbreak. The number of stents placed during the first half of the SARS-CoV-2 outbreak (from the 10 th day to the 35 th day) was also identified. All participating centers were tertiary care centers, with significant experience and expertise in upper gastrointestinal stenting.

Information on patient demographic characteristics (age and gender), medical history (disease-causing luminal obstruction, cTNM staging, patient cardiovascular and respiratory comorbidities), renal failure at presentation, ASA classification, hospitalization before SEMS placement, SEMS indication (esophageal dysphagia or gastric outlet obstruction) and dysphagia grade (Takita's dysphagia grading [11]) or gastric outlet obstruction scoring system (GOOSS) [12] before and 7 days after SEMS placement was collected from medical records. In addition, we collected data on procedural characteristics, such as stricture location and diameter, and specifics of each procedure, such as SEMS characteristics and scope used. We also collected information on the cumulative number of SARS-CoV-2 cases at each hospital and respective country during the study period, COVID impact on each endoscopic unit (number of procedures performed, endoscopists, nurses and infected personal in the unit), number of people in the endoscopic suite during SEMS placement, fellow participation, use of PPE, use of endoscopic suites with negative pressure or air purifiers, as well as COVID status/symptoms of endoscopists, nurses, and anesthesiologists before and 14 days after the SEMS procedure.

Each center used its own clinical decision making regarding which type of stent to use. SEMS placed were nitinol stents, uncovered, partially covered or fully covered, with body diameters ranging from $18 \mathrm{~mm}$ to $24 \mathrm{~mm}$. SEMS were deployed under moderate or deep sedation at the discretion of the endoscopist. They were deployed over-the-wire or through-thescope. Tumor length was estimated endoscopically or radiologically using contrast medium injection. A stent measuring 2 to $4 \mathrm{~cm}$ longer than the stricture was used to allow for a 1 - to 2-cm extension above and below the proximal and distal tumor borders. Technical success of SEMS placement was defined as successful deployment of the SEMS in the correct position. Adverse events (AEs) were recorded. All dates of disease diagnosis, hospitalization, SEMS placement, beginning of oral diet, hospital discharge and AEs were recorded.

\section{Statistical analysis}

Categorical variables were described using absolute and relative frequencies, while continuous variables were described using means and standard deviations or medians and interquartile ranges (IQR). Comparison of patient characteristics during the COVID outbreak period and the year before was performed using a Mann-Whitney $U$ test for continuous variables and a chisquare test for categorical variables. All reported $P$ values were two-sided and $P<0.05$ was considered statistically significant. Analyses were performed using SPSS 23.0 (IBM Corp., Armonk, New York, United States).

\section{Results}

\section{Patient characteristics and SEMS outcomes (2020)}

Twenty-nine patients were included. Baseline characteristics of the patients in whom a SEMS was placed and procedure characteristics and related outcomes are summarized in $>$ Table 1 and - Table 2. Median age was 68 years (IQR 62-71), with 13 patients (45\%) being female. Most obstructions were caused by esophageal cancer $(n=11 ; 38 \%)$, followed by gastric cancer $(n=8 ; 28 \%)$ and pancreatic cancer $(n=6 ; 21 \%)$. Cardiovascular and respiratory comorbidities were present in 13 (45\%) and 4 (14\%) patients, respectively. Only four (14\%) of the SEMS were placed in patients with altered anatomy, while three patients (10\%) had a previous SEMS placed for the same indication ( Table 1). 
- Table 1 Baseline characteristics of patients with upper gastrointestinal obstruction who underwent luminal stenting.

\begin{tabular}{|c|c|c|c|}
\hline & \multicolumn{3}{|l|}{ Global $(n=41)$} \\
\hline & $2020(n=29)$ & $2019(n=12)$ & $P$ value \\
\hline Female gender (n, \%) & $13(44.8 \%)$ & $1(8.3 \%)$ & 0.033 \\
\hline Age (median, IQR) & $68(62-71)$ & $69(62-76)$ & 0.877 \\
\hline \multicolumn{3}{|l|}{ Gastrointestinal disease (n, \%) } & \multirow[t]{6}{*}{0.380} \\
\hline - Esophageal cancer & $11(37.9 \%)$ & $5(41.7 \%)$ & \\
\hline - Esophageal extrinsic compression & $2(6.9 \%)$ & $2(16.7 \%)$ & \\
\hline - Gastric cancer & $8(27.6 \%)$ & $3(25 \%)$ & \\
\hline - Pancreatic cancer & $6(20.7 \%)$ & - & \\
\hline - Other ${ }^{1}$ & $2(6.9 \%)$ & $2(16.7 \%)$ & \\
\hline \multicolumn{3}{|l|}{ Tstaging (n, \%) } & \multirow[t]{6}{*}{0.650} \\
\hline . 1 & $1(3.4 \%)$ & - & \\
\hline .2 & $1(3.4 \%)$ & $1(8.3 \%)$ & \\
\hline .3 & $9(31 \%)$ & $6(50 \%)$ & \\
\hline .4 & $16(55.2 \%)$ & $4(33.3 \%)$ & \\
\hline - Unknown & $2(6.9 \%)$ & $1(8.3 \%)$ & \\
\hline \multicolumn{3}{|l|}{$N$ staging (n, \%) } & \multirow[t]{4}{*}{0.649} \\
\hline .0 & $6(20.7 \%)$ & $1(8.3 \%)$ & \\
\hline - $\geq 1$ & $21(72.4 \%)$ & $10(83.3 \%)$ & \\
\hline - Unknown & $2(6.9 \%)$ & $1(8.3 \%)$ & \\
\hline \multicolumn{3}{|l|}{ M staging (n, \%) } & \multirow[t]{4}{*}{0.439} \\
\hline . 0 & $10(34.5 \%)$ & $6(50 \%)$ & \\
\hline . 1 & $17(58.6 \%)$ & $5(41.7 \%)$ & \\
\hline - Unknown & $2(6.9 \%)$ & $1(8.3 \%)$ & \\
\hline ASA classification (median, IQR) & $2(2-3)$ & $3(2-3)$ & 0.300 \\
\hline \multicolumn{4}{|l|}{ Comorbidities (n, \%) } \\
\hline - Cardiovascular & $13(44.8 \%)$ & $9(75 \%)$ & 0.098 \\
\hline - Respiratory & $4(13.8 \%)$ & $5(41.7 \%)$ & 0.093 \\
\hline \multicolumn{3}{|l|}{ Anatomy (n, \%) } & \multirow[t]{4}{*}{0.058} \\
\hline - Normal & $25(86.2 \%)$ & $9(75 \%)$ & \\
\hline - Esophagojejunal anastomosis & $1(3.4 \%)$ & $1(8.3)$ & \\
\hline - Gastrojejunal anastomosis & $3(10.3 \%)$ & $2(16.7 \%)$ & \\
\hline Previous SEMS placed for same indication & $3(10.3 \%)$ & $2(16.7 \%)$ & 0.620 \\
\hline \multicolumn{3}{|l|}{ SEMS indication (n, \%) } & \multirow[t]{3}{*}{0.325} \\
\hline - Esophageal dysphagia & $14(48.3 \%)$ & $8(66.7 \%)$ & \\
\hline - Gastric outlet obstruction & $15(51.7 \%)$ & $4(33.3 \%)$ & \\
\hline \multicolumn{4}{|l|}{ Esophageal dysphagia } \\
\hline - Time from dysphagia onset to SEMS placement in days (days; median, IQR) & $32(15-25)$ & $71(18-408)$ & 0.658 \\
\hline - Patient hospitalization (n, \%) & $5(35.7 \%)$ & $6(75 \%)$ & 0.183 \\
\hline - Renal failure at presentation (n, \%) & $0(0 \%)$ & $3(37.5 \%)$ & 0.036 \\
\hline
\end{tabular}


$>$ Table 1 (Continuation)

\begin{tabular}{|c|c|c|c|}
\hline & \multicolumn{3}{|l|}{ Global $(n=41)$} \\
\hline & $2020(n=29)$ & $2019(n=12)$ & $P$ value \\
\hline - Takita grade before SEMS (median, IQR) & $4(3-5)$ & $4(4-5)$ & 0.920 \\
\hline - Stricture estimated diameter, mm (median, IQR) & $6(5-9)$ & $9(6-11)$ & 0.659 \\
\hline \multicolumn{4}{|l|}{ Gastric outlet obstruction } \\
\hline $\begin{array}{l}\text { - Time from obstructive symptoms onset to SEMS placement in days (median, } \\
\text { IQR) }\end{array}$ & $12(5-29)$ & $10(4-14)$ & 0.477 \\
\hline - Patient hospitalization (n, \%) & $14(93.3 \%)$ & $3(75 \%)$ & 0.386 \\
\hline - Renal failure at presentation (n, \%) & $3(20 \%)$ & $0(0 \%)$ & 1.000 \\
\hline - GOOSS before SEMS (median, IQR) & $0(0-1)$ & $1(1-2)$ & 0.037 \\
\hline - Stricture estimated diameter, mm (median, IQR) & $5(3-9)$ & $6(3-9)$ & 0.736 \\
\hline
\end{tabular}

- Table 2 Procedure characteristics and related outcomes.

\begin{tabular}{|c|c|c|c|}
\hline & \multicolumn{3}{|l|}{ Global $(n=41)$} \\
\hline & $2020(n=29)$ & $2019(n=12)$ & $P$ value \\
\hline \multicolumn{3}{|l|}{ Stricture location (n, \%) } & \multirow[t]{10}{*}{0.116} \\
\hline - Upper/mid esophagus & $7(24.1 \%)$ & $3(25 \%)$ & \\
\hline - Distal esophagus/cardia & $7(24.1 \%)$ & $5(41.7 \%)$ & \\
\hline - Gastric body & $3(10.3 \%)$ & - & \\
\hline - Gastric antrum & $4(13.8 \%)$ & - & \\
\hline - Duodenal bulb & $1(3.4 \%)$ & $1(8.3 \%)$ & \\
\hline - Second portion of duodenum & $5(17.2 \%)$ & $1(8.3 \%)$ & \\
\hline - Third portion of duodenum & $1(3.4 \%)$ & - & \\
\hline " Jejunum & - & $2(16.7 \%)$ & \\
\hline - Gastrojejunal anastomosis & $1(3.4 \%)$ & - & \\
\hline \multicolumn{3}{|l|}{ Scope used for SEMS placement (n, \%) } & \multirow[t]{5}{*}{0.749} \\
\hline - Gastroscope & $8(27.6 \%)$ & $4(33.3 \%)$ & \\
\hline - Therapeutic gastroscope & $15(51.7 \%)$ & $5(41.7 \%)$ & \\
\hline - Duodenoscope & $1(3.4 \%)$ & - & \\
\hline - Ultrathin scope & $5(17.2 \%)$ & $3(25 \%)$ & \\
\hline \multicolumn{3}{|l|}{ SEMS placement technique (n, \%) } & \multirow[t]{3}{*}{0.272} \\
\hline " TTS & $17(58.6 \%)$ & $7(58.3 \%)$ & \\
\hline - Over-the-wire & $12(41.4 \%)$ & $5(41.6 \%)$ & \\
\hline SEMS body diameter (median, mm) & $20(18-22)$ & $22(19-22.5)$ & 0.475 \\
\hline SEMS flange diameter (median, mm) & $26(24-26)$ & $26.5(24-27.5)$ & 0.358 \\
\hline SEMS length (median, mm) & $110(89-121.5)$ & $105(100-120)$ & 0.919 \\
\hline Fluoroscopy use (n, \%) & $26(89.7 \%)$ & $9(75 \%)$ & 0.334 \\
\hline
\end{tabular}


- Table 2 (Continuation)

\begin{tabular}{|c|c|c|c|}
\hline & \multicolumn{3}{|l|}{ Global $(n=41)$} \\
\hline & $2020(n=29)$ & $2019(n=12)$ & $P$ value \\
\hline \multicolumn{3}{|l|}{ Sedation (n, \%) } & \multirow[t]{4}{*}{0.166} \\
\hline - Conscious sedation & $10(34.5 \%)$ & $2(16.7)$ & \\
\hline - Deep sedation & $19(65.5 \%)$ & $9(75 \%)$ & \\
\hline - General anesthesia & - & $1(8.3 \%)$ & \\
\hline Technical success (n, \%) & $29(100 \%)$ & $12(100 \%)$ & 1.000 \\
\hline \multicolumn{4}{|l|}{ Esophageal dysphagia } \\
\hline - Takita grade 1 week after (median, IQR) & $2(2-3)$ & $2(2-2)$ & 0.212 \\
\hline - Time from SEMS placement to beginning of oral diet in days (median, IQR) & $1(1-1)$ & $1(0-2)$ & 0.602 \\
\hline - Time from SEMS placement to hospital discharge in days (median, IQR) & $2(0-3)$ & $3(0-9)$ & 1.000 \\
\hline \multicolumn{4}{|l|}{ Gastric outlet obstruction } \\
\hline - GOOSS 1 week after (median, IQR) & $2(2-3)$ & $3(3-3)$ & 0.124 \\
\hline - Time from SEMS placement to beginning of oral diet in days (median, IQR) & $1(1-1)$ & $1(1-2)$ & 0.885 \\
\hline - Time from SEMS placement to hospital discharge in days (median, IQR) & $2(1-5)$ & $3(2-6)$ & 0.810 \\
\hline Adverse event (n, \%) & $5(17 \%)$ & $2(16.7 \%)$ & \multirow[t]{6}{*}{0.983} \\
\hline Pain & $1(3.4 \%)$ & $1(8.3 \%)$ & \\
\hline Overgrowth/ingrowth & $2(6.9 \%)$ & - & \\
\hline Bleeding & $1(3.4 \%)$ & - & \\
\hline Nausea/vomiting & $1(3.4 \%)$ & - & \\
\hline Migration & - & $1(8.3 \%)$ & \\
\hline $\begin{array}{l}\text { Time from SEMS placement to AE } \\
\text { (median, days) }\end{array}$ & $2(2-22)$ & $13(0-25)$ & 0.095 \\
\hline
\end{tabular}

The majority of SEMS were placed using therapeutic gastroscopes $(n=15 ; 52 \%)$, followed by conventional gastroscopes $(n=8 ; 28 \%)$ and ultrathin scopes $(n=5 ; 17 \%)$. SEMS placement technique was through-the-scope in 17 patients (59\%) and over-the-wire in the remaining 12 (41\%). Technical success was achieved in all patients, with Takita grades and GOOSS at 1 week after SEMS placement improving to a median of 2 (IQR $2-3$ ) in both scores. Early AEs were reported in 5 patients (17\%), after a median of 2 days (IQR 2-22) ( $>$ Table 2 ).

\section{Mitigation measures impact}

From the $35^{\text {th }}$ day to the $60^{\text {th }}$ day after the first reported case of SARS-CoV-2 in each country, a total of 1028 endoscopic procedures were performed in the six European centers (median of 161.5 procedures). This corresponds to a reduction of $80 \%$ compared to the same time period in 2019, when a total of 5174 endoscopic procedures were performed (median of 799.5 procedures). The number of endoscopists and nurses working in the endoscopy department during the study period also dropped by $70 \%$ and $56 \%$, respectively. The burden of SARS-CoV-2 cases varied among hospitals, with admissions ranging from $0.03 \%$ to $3.8 \%$ of the total number of national cases ( $\triangleright$ Table 3 ).

A total of 29 SEMS were placed for upper gastrointestinal obstruction (esophageal dysphagia: 48.3\% [ $n=14]$ and gastric outlet obstruction: $51.7 \%[\mathrm{n}=15]$ ) during the study period, corresponding to an increase of $241 \%$ compared to the same time period in 2019, when a total of 12 SEMS were placed.

With the exception of renal failure in patients with esophageal dysphagia, which was significantly higher in 2019 (0 [0\%] vs 3 [38\%]; $P=0.036)$, and GOOSS before SEMS placement in patients with gastric outlet obstruction, which was significantly lower in 2020 (0 [0-1] vs 1 [1-2]; $P=0.037)$, no other significant differences were found between the two time periods regarding median time from dysphagia/obstructive symptoms onset to SEMS placement, hospitalization, stricture estimated diameter, Takita grade before SEMS placement, beginning of oral diet and hospital discharge ( $\triangleright$ Table 1 and $\triangleright$ Table 2 ). 


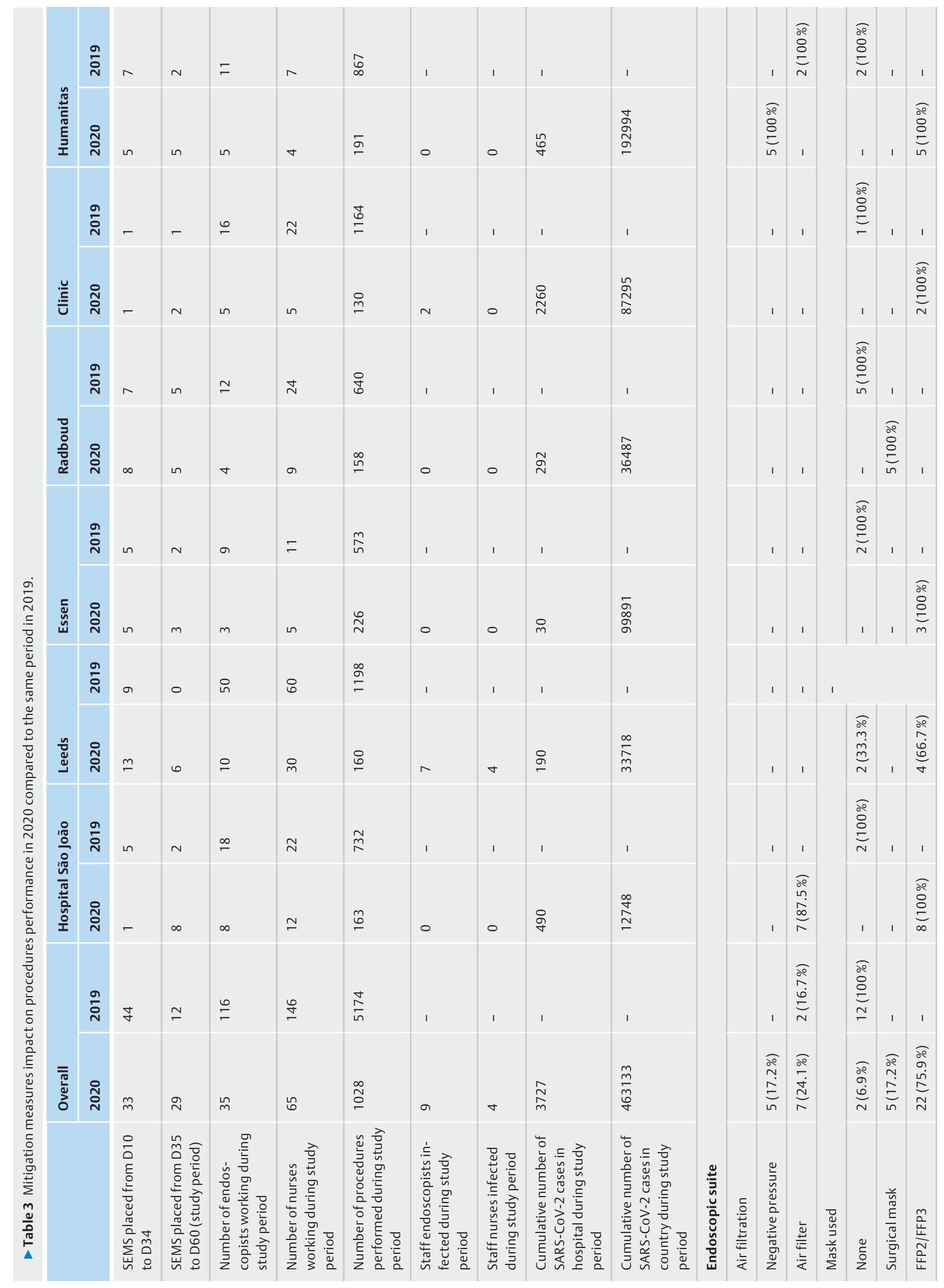




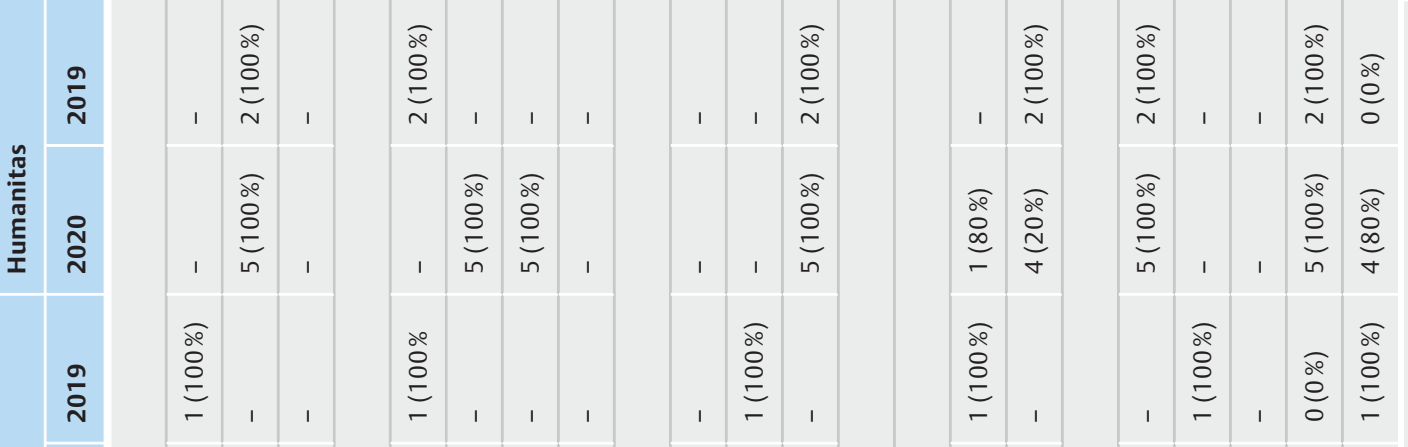

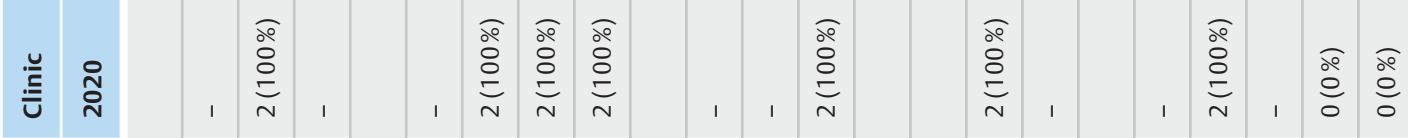

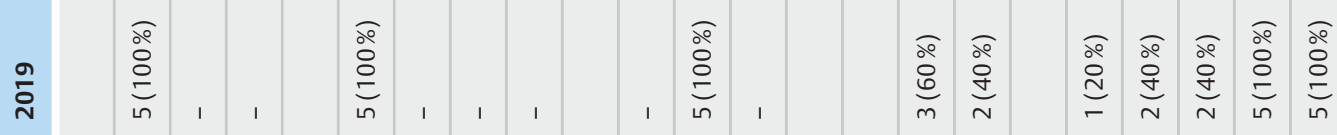

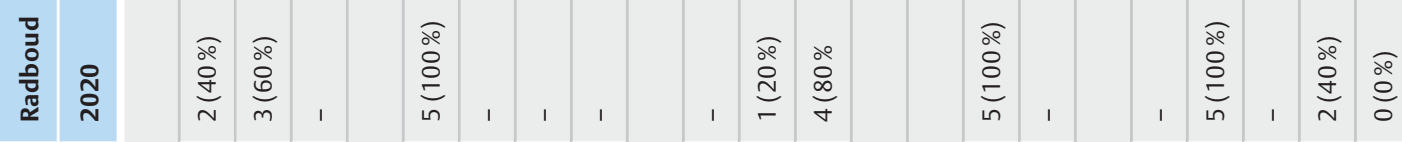

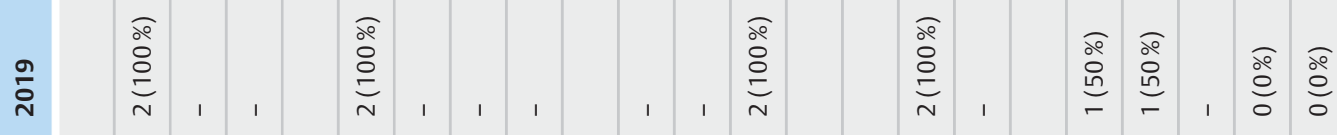

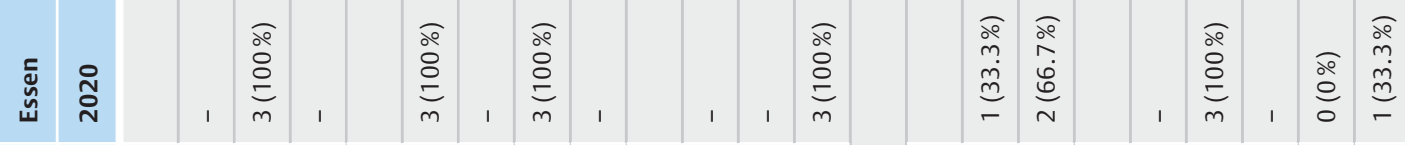

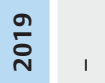

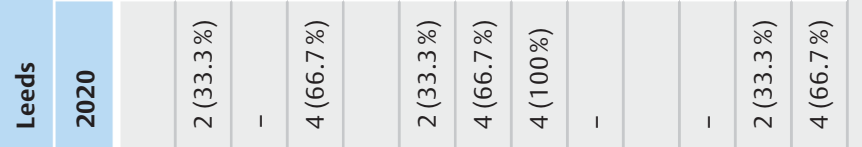

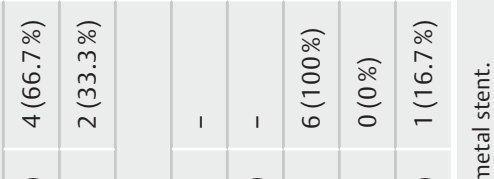

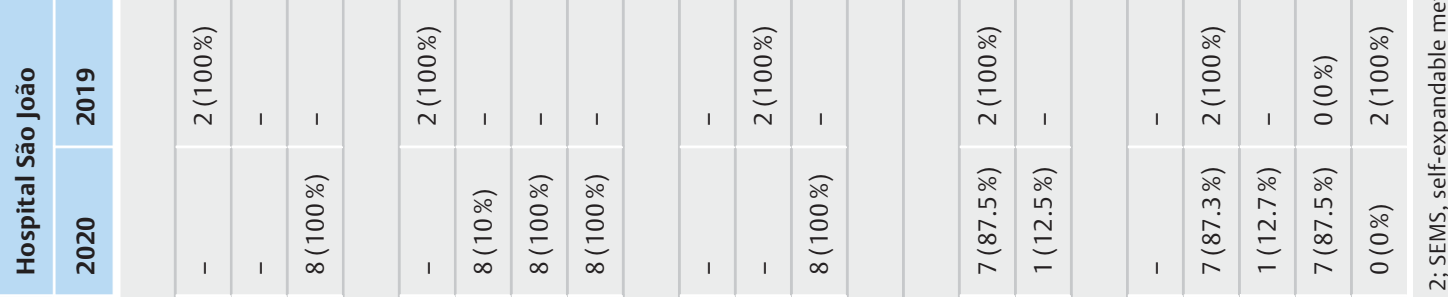

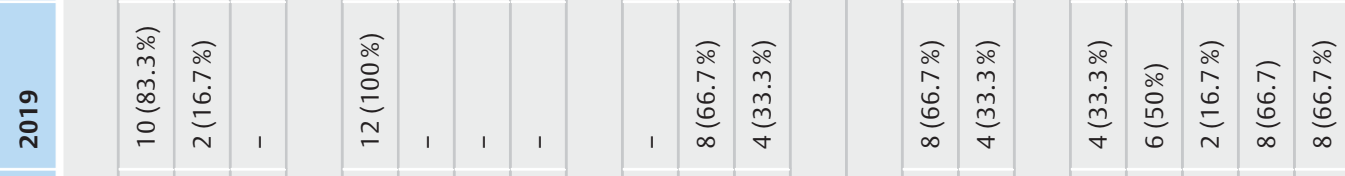

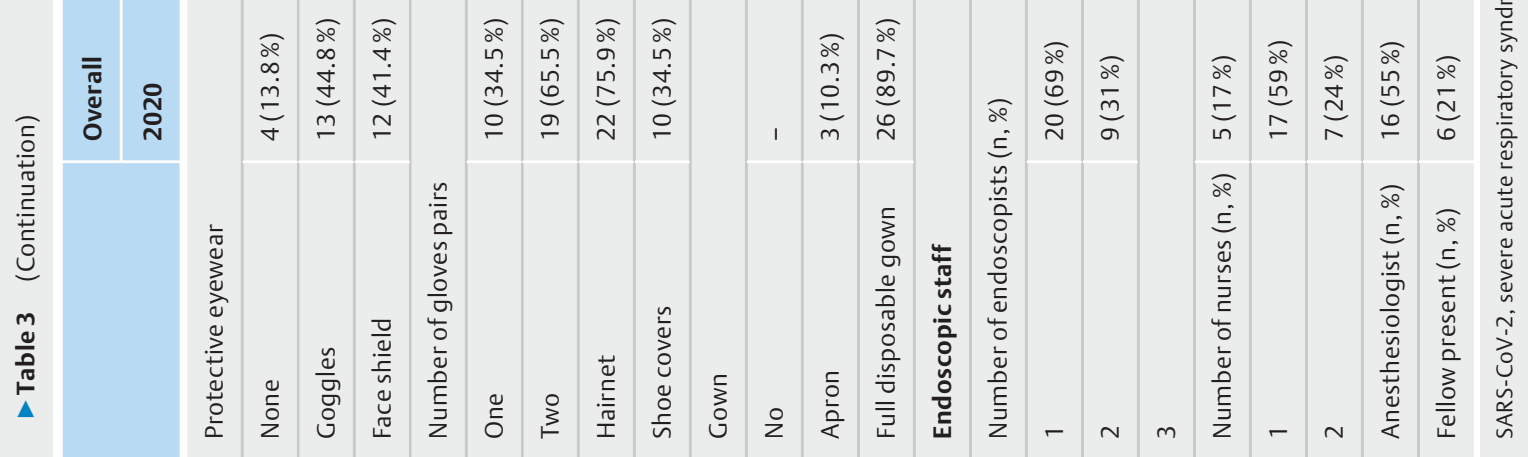




\section{Endoscopic staff and personal protection equipment}

The endoscopic procedures were performed in rooms with negative pressure in $17 \%$ of the cases, with an additional $17 \%$ being performed in rooms with air purifiers ( $>$ Table 3 ).

No significant differences were found between the two time periods regarding the number of endoscopists in the endoscopic suite (2020: one endoscopist 69\% vs 2019: one endoscopist $67 \%$ ), nurses and anesthesiologists (2020: $55 \%$ vs 2019: $67 \%)$. However, fellows' involvement was significantly lower in 2020 (21\% vs $67 \%$; $P=0.01)$ ( Table 3 ).

Regarding PPE, in 2020, the majority of procedures were performed using facial masks (FFP2/FFP3 in $76 \%$ and surgical masks in $17 \%$ ), protective eyewear (goggles in $45 \%$ and face shield in $41 \%$ ), two pairs of gloves (65\%), hairnet (76\%) and full disposable gowns (90\%); shoe covers were used in $34 \%$ of the procedures. In 2019, all procedures were performed without facial mask, hairnet or shoe covers, and only one pair of gloves; most procedures were performed without protective eyewear (83\%) and with aprons only (67\%) (ฉ Table 3 ).

\section{COVID-19 status}

In 2020, no SEMS procedures were performed in COVID-19confirmed patients, but $55 \%$ of the patients were not tested for SARS-CoV-2 before the procedure ( $\downarrow$ Table 4 ); even though two patients $(7 \%)$ presented with respiratory symptoms and one (3\%) had fever before SEMS placement, and all of them were real-time polymerase chain reaction (RT-PCR) test-negative. One patient ( $3 \%$ ) tested positive for SARS-CoV-2 after the procedure and two patients (7\%) reported respiratory symptoms up to 14 days after SEMS placement ( $>$ Table 4 ).

The majority of endoscopists ( $86 \%)$, nurses (76\%), and anesthesiologists ( $87 \%$ ) were not tested for SARS-CoV-2 before the procedure. No medical staff involved in the SEMS procedures developed COVID-19 14 days after the procedure ( $\triangleright$ Table 4 ). However, nine of 35 endoscopists and four of 65 nurses involved in other procedures got infected during the overall study period ( $\triangleright$ Table 3 ).

\section{Discussion}

The COVID-19 pandemic has been and still is affecting daily practice of gastrointestinal endoscopy worldwide. Several recommendations and statements have already been published in order to ensure safety of patients and endoscopy unit personnel [2-6]. With the significant increase in hospital admissions of COVID-19 patients, European hospitals have markedly reduced elective endoscopies, and the majority of resources have been directed to the COVID-19 pandemic. A recent survey reported a reduction in endoscopic volume of $91 \%$ compared to the volume before the COVID-19 outbreak [13]. In our study, a drop of $80 \%$ in the number of endoscopic procedures was noticed. The number of endoscopists and nurses working in the endoscopy department also dropped by $70 \%$ and $56 \%$, respectively. However, the number of staff involved in SEMS placement was not impacted, with similar numbers of endoscopic staff present in the endoscopic suite compared to 2019. Nonetheless, fellows' participation in SEMS placement reduced from $67 \%$ to $21 \%$. This can be explained by the demand for stringent standards of infection control, rationing the use of necessary PPE [14] and redeployment of fellows to support critical services of each hospital as a result of the COVID-19 pandemic.

It is unknown for how long the COVID-19 pandemic will last. Despite a universal desire to return to usual endoscopic and clinical care, patients may still avoid undergoing scheduled endoscopic procedures because of fear of being infected by SARS-CoV-2, but likely also because they consider it safe to further postpone an endoscopic procedure. It has been reported in Italy that up to $30 \%$ of patients do not show up to the endoscopic unit despite being scheduled [15]. Nonetheless, in our study, patients with symptomatic obstruction did not seem to have avoided or delayed going to the hospital. An increase of $241 \%$ (from 12 to 29 ) in the number of SEMS placements was observed when compared to the same time period in 2019. The reason for this unexpected increase remains uncertain. Potentially, it could be related to a lower number of interventional cases in 2019; however, it could also reflect a change of practice in oncology during COVID times, with more patients being referred for definitive palliation rather than being considered for chemo- and/or radiotherapy due to fear of increased risks or lack of capacity to administer it. There were relatively more T4 patients in 2020, which could suggest that some patients have waited longer themselves or had to wait for treatment with chemotherapy and/or radiotherapy. In addition, $40 \%$ of the patients had no metastases at presentation, which could suggest that chemotherapy and/or radiotherapy had indeed been delayed or not performed due to a preferred choice for COVID-19 care in the hospital. As the number of procedures was small, we do not have sufficient evidence to support any solid conclusion. Of interest, major patient baseline characteristics and post-stenting management policies did not differ between the two time periods.

The risk of COVID-19 after endoscopic procedures and the risk factors associated with it have not yet been established. Endoscopy presents a source of aerosolization, potentially increasing the risk of infection with SARS-CoV-2 for endoscopy staff; however, preliminary reports suggest a low risk for professional and patient infection [16]. Repici et al [17] reported only one confirmed case of COVID-19 in 802 patients who underwent an endoscopic procedure. Although we did not place SEMS in COVID-19-confirmed patients, $55 \%$ of the patients were not tested for SARS-CoV-2 before the procedure. Only one patient tested positive for SARS-CoV-2 after the procedure; however, he had not been tested before. None of the medical staff involved in the SEMS procedures developed COVID-19 symptoms, even though $26 \%$ of endoscopists and $6 \%$ of nurses involved in other procedures got infected during the study period; however, the source of their infection has not been elucidated. These findings are in line with a recent Italian report describing the rate of COVID-19 infected physicians in gastroenterology units [18]. The entire gastroenterology department of Hospital São João in Portugal underwent serological testing at the end of the study, with the results being nega- 


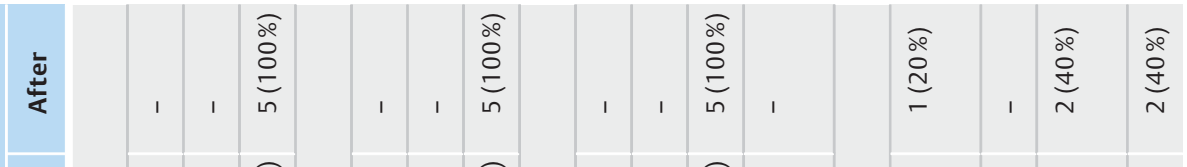

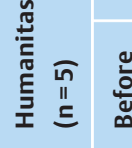

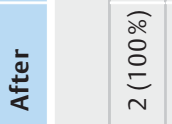

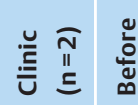

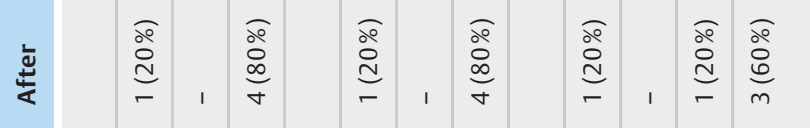

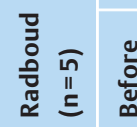

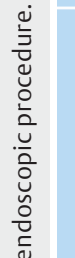

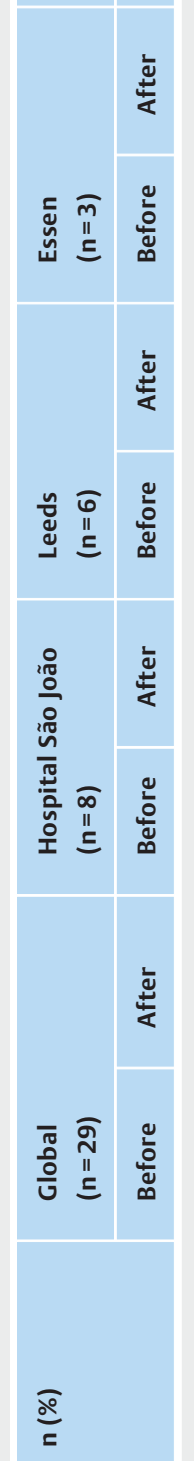

$\widehat{d}$
ơd
d

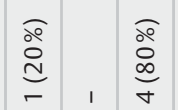

$\frac{\substack{d \\ \stackrel{d}{d}}}{d}$

高

ஓ̊

ஓ̊

ஃ̊ํำ

ฮ̊ำ

๖̊ำ

๑̊ำ

$\underset{\infty}{\stackrel{\circ}{\circ}}$

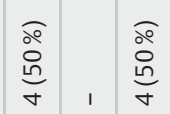

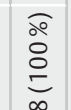

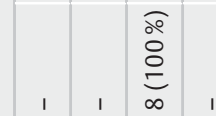

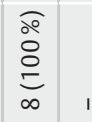

๖ำ

ㅇํㅇ

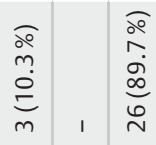

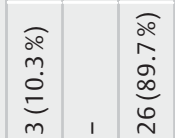

ֻัฐ

\begin{tabular}{l|} 
ळ̊ \\
$\stackrel{0}{0}$ \\
$\infty$ \\
$\infty$
\end{tabular}

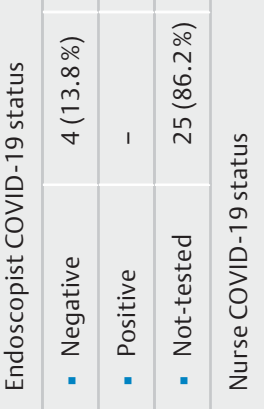

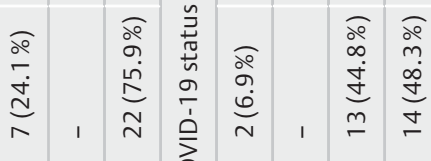

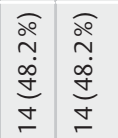

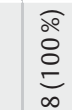

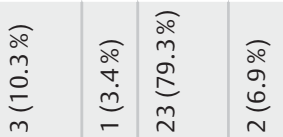

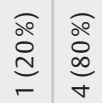

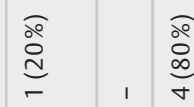
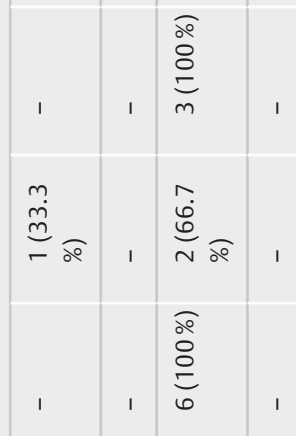

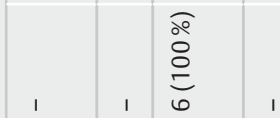

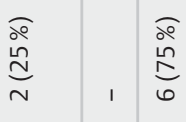

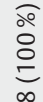

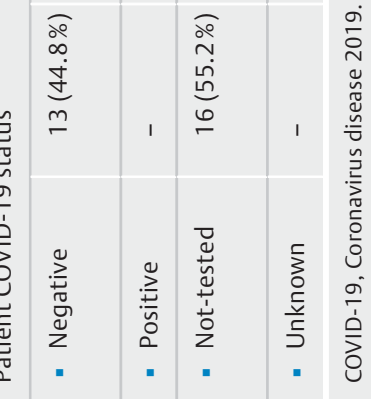


tive for all of them. Infection prevention and control has been shown to be highly effective in assuring the safety of both HCP and patients [19-22]. In our study, negative pressure or rooms with air purifiers were only available in $34 \%$ of the procedures; $76 \%$ and $17 \%$ of our procedures were performed with FFP2/ FFP3 and surgical masks, respectively. In one of the hospitals, due to a shortage of PPE, FFP2 masks were only allowed for RTPCR-positive cases or for highly suspicious but test-negative cases. While a recent guideline has suggested that surgical masks can be used in this setting [23], there remains a significant false-negative rate for RT-PCR testing and concern for infection between the time of testing and the procedure. Protective eyewear, offering additional protection against aerosol droplets from patients [24], was also used in $86 \%$ of the procedures.

Limitations of our study include its retrospective design, being conducted in six tertiary referral centers. None of the patients included were, as far as we know, COVID-19-positive, so it is not possible to assess whether the risk of HCP infection after therapeutic endoscopy is higher when performed in confirmed COVID-19 patients. Nonetheless, we present data from centers for which the SARS-CoV-2 outbreak had a major impact on their endoscopic activity during the outbreak period and were located in geographical areas with high rates of community transmission.

\section{Conclusion}

This is the first multicenter international study to quantify the impact of COVID-19 on endoscopic placement of SEMS in patients with upper gastrointestinal obstruction. Upper gastrointestinal stenting increased during the SARS-CoV-2 outbreak period. This could be related to yearly variation in the number of procedures (unrelated to the pandemic) or reflect a change of oncologic treatment practice during COVID times.

\section{Competing interests}

Dr. Repici is a consultant for Boston Scientific, ERBE, Fujifilm, Medtronic, EndoKey, EndoStart and Q3Medical. Dr. Ginès is an advisor for Boston Scientific and Olympus Europe. Dr. Siersema receives research support from MicroTech (China) and Pentax (Japan). He previously received research support from Boston Scientific (US), Cook Medical (Ireland), and EllaCS (Czech Republic).

\section{References}

[1] Maida M, Sferrazza S, Savarino E et al. Italian Society of Gastroenterology (SIGE). Impact of the COVID-19 Pandemic on Gastroenterology Divisions in Italy: A National Survey. Dig Liver Dis 2020: doi:10.1016/j.dld.2020.05.017

[2] New York Society for Gastrointestinal Endoscopy. New York Society for Gastrointestinal Endoscopy Guidelines for Endoscopy Units during the COVID-19 Pandemic. 2020: Available from: https://www.nysge. org//Files/NYSGE\%20Guidelines\%20for\%20Endoscopy\%20Units\% 20During\%20the\%20COVID-19\%20Pandemic.pdf
[3] British Society of Gastroenterology. Advice for Endoscopy Teams during COVID-19. 2020: Available from: https://www.bsg.org.uk/ covid-19-advice/endoscopy-activity-and-covid-19-bsg-and-jag-guidance/

[4] Irisawa A, Furuta T, Matsumoto T et al. Gastrointestinal endoscopy in the era of the acute pandemic of COVID-19: Recommendations by Japan Gastroenterological Endoscopy Society. Digest Endosc 2020; 32: 648-650

[5] Gralnek IM, Hassan C, Beilenhoff U et al. ESGE and ESGENA Position Statement on gastrointestinal endoscopy and the COVID-19 pandemic. Endoscopy 2020; 52: 483-490

[6] Chiu PWY, Ng SC, Inoue $\mathrm{H}$ et al. Practice of endoscopy during COVID19 pandemic: position statements of the Asian Pacific Society for Digestive Endoscopy (APSDE-COVID statements). Gut 2020; 69: 991996

[7] Soetikno R, Teoh AY, Kaltenbach T et al. Considerations in performing endoscopy during the COVID-19 pandemic. Gastrointest EndosC 2020; 92: 176-183

[8] European Center for Disease Prevention and Control. https://www. ecdc.europa.eu/sites/default/files/documents/covid-19-publichealth-management-contact-novel-coronavirus-cases-EU.pdf

[9] Spaander MC, Baron TH, Siersema PD et al. Esophageal stenting for benign and malignant disease: European Society of Gastrointestinal Endoscopy (ESGE) Clinical Guideline. Endoscopy 2016; 48: 939-948

[10] Nassif T, Prat F, Meduri B et al. Endoscopic palliation of malignant gastric outlet obstruction using self-expandable metallic stents: results of a multicenter study. Endoscopy 2003; 35: 483-489

[11] Peters JH, Meester TR, Stein HJ. Surgical therapy for cancer of the esophagus and cardia. In: Castell DO. The Esophagus, 2nd edn. New York: Little, Brown; 1995: 293-335

[12] Adler DG, Baron TH. Endoscopic palliation of malignant gastric outlet obstruction using self expanding metal stents: experience in $36 \mathrm{pa}-$ tients. Am J Gastroenterol 2002; 97: 72-78

[13] Marasco M, Nardone OM, Maida M et al. Impact of COVID-19 outbreak on clinical practice and training of young gastroenterologists: a European Survey. Dig Liver Dis 2020: [Epub ahead of print] doi:10.1016/ j.dld.2020.05.023

[14] Lui RN, Wong SH, Sanchez-Luna SA et al. Overview of guidance for endoscopy during the coronavirus disease 2019 pandemic. J Gastroenterol Hepatol 2020; 35: 749-759

[15] Armellini E, Repici A, Alvisi C et al. Fast Track Endoscopy Study Group. Analysis of patients attitude to undergo urgent endoscopic procedures during COVID-19 outbreak in Italy. Dig Liver Dis 2020: doi:10.1016/j.dld.2020.05.015

[16] Ginès A, Fernández-Esparrach G, Pellisé M et al. Critical importance of early introduction of prevention measures for SARS-CoV-2 infection in endoscopy units. Gastrointest Endosc 2020: doi:10.1016/j. gie.2020.06.023

[17] Repici A, Aragona G, Cengia G et al. Italian GI-COVID19 Working Group. Low risk of covid-19 transmission in Gl endoscopy. Gut 2020; 69: 1925-1927. doi:10.1136/gutjnl-2020-321341

[18] Repici A, Pace F, Gabbiadini R et al. Endoscopy units and the COVID-19 Outbreak: a multi-center experience from Italy. Gastroenterology 2020: doi:10.1053/j.gastro.2020.04.003

[19] European Centre for Disease Prevention and Control. Infection prevention and control and preparedness for COVID-19 in healthcare settings. 2020: https://www.ecdc.europa.eu/en/publications-data/ infection-prevention-and-control-and-preparedness-covid-19healthcare-settings

[20] European Centre for Disease Prevention and Control. Guidance for wearing and removing personal protective equipment in healthcare 
settings for the care of patients with suspected or confirmed COVID19. https://www.ecdc.europa.eu/en/publicationsdata/guidancewearing-and-removing-personal-protective-equipment-healthcaresettings

[21] Zhang $Y$, Zhang $X$, Liu $L$ et al. Suggestions for infection prevention and control in digestive endoscopy during current 2019-nCoV pneumonia outbreak in Wuhan, Hubei province, China. Endoscopy 2020; 52: 312-314

[22] World Health Organization. Infection prevention and control during health care when novel coronavirus ( $\mathrm{nCoV}$ ) infection is suspected. https://www.who.int/publications-detail/infection-prevention-andcontrol-during-health-carewhen-novel-coronavirus-(ncov)-infectionis-suspected-20200125

[23] Joint AGA/DHPA Guidance: Recommendations for Resumption of Elective Endoscopy During the COVID-19 Pandemic. 2020: Available from (cited 2020 May 12): https://www.dhpassociation.org/2020/04/ 27/aga-dhpa-resume-endoscopy-covid19/

[24] Sagami R, Nishikiori H, Sato T et al. Endoscopic Shield: barrier enclosure during the endoscopy to prevent aerosol droplets during the COVID-19 pandemic. VideoGIE 2020: doi:10.1016/j. vgie.2020.05.002 